\title{
Subsurface Microbial Iron- Reduction Processes in the Formation of Iron Ore Caves
}

\author{
Hazel A. BARTON ${ }^{1,3 *}$, Ceth W. PARKeR ${ }^{2}$, SATOSHI \\ KAWAICHI $^{1}$, MELISSA MULFORD ${ }^{1}$, JOHN M. SENKO ${ }^{1,3}$, \\ Augusto S. Auler ${ }^{4}$, Ira D. SAsOWSKY 3 \\ ${ }^{1}$ Integrated Bioscience, Uni. Akron, Akron, $\mathrm{OH}$ \\ (correspondance: bartonh@uakron.edu) \\ ${ }^{2}$ NASA Jet Propulsion Laboratory, Pasadena, CA. \\ ${ }^{3}$ Department of Geosciences, Uni. Akron, Akron, $\mathrm{OH}$ \\ ${ }^{4}$ Instituto do Carste, Belo Horizonte, MG, Brazil.
}

The Quadrilátero Ferrífero (Iron Quadrangle) of Brazil contains expansive deposits of an ancient $(22.4-2.6 \mathrm{Gyr})$ banded iron formation (BIF) known as itabirite, which hosts one of the most significant iron-ore deposits in the world. The iron ore deposits post-date BIF formation by almost 2.0 Gyr, and understanding the mechanisms of ore genesis is complicated by its association with canga (a 2-4 m thick, surficial layer of weathered BIF cemented by iron oxides). The extremely weathering-resistant nature of the canga (denudation rate $\sim 0.16-0.54 \mathrm{~m} \mathrm{Myr}^{-1}$ ) is in direct contrast to the presence of associated caves at the canga-BIF interface (some of which exceed $1,000 \mathrm{~m}$ in length with passage dimensions approaching $10 \mathrm{~m}$, suggesting aggressive dissolution is occuring at the canga/BIF interface. Using in situ measurements, we have demonstrated the presence of $\mathrm{Fe}(\mathrm{III})$-reducing microorganisms (FeRM) behind the walls of these caves, and used computer tomography to show that this activity is protected from the oxygenated-atmosphere of the cave by an Fe(III) oxide crust. This FeRM activity behind the walls allows the mass removal of Fe as soluble Fe(II), which has been quantitated via optical profilometry, and the accumulation of a $\mathrm{Fe}(\mathrm{II})$-depleted material (termed sub muros). The accumulation of sub muros leads to repeated episodes of wall collapse and the formation of cave voids in a previously undescribed process. Cultivation experiments and electrochemistry have confirmed the presence of FeRM species within the sub muros, and provided a potential mechanism for microbially-mediated silica dissolution, generating the initial porosity within the BIF for FeRM activities. Our data suggest that such FeRM activity could be responsible for mobilizing as much as $123,000 \mathrm{~kg}$ of $\mathrm{Fe}(\mathrm{II})$ into the groundwater per $\mathrm{km}^{2}$ of itabirite, and represents an underestimated contribution to modern continental and marine Fe budgets. 